\title{
METODOLOGIA SIMPLIFICADA PARA AVALIAÇÃO DO POTENCIAL DE ENERGIA EÓLICA EM CENTROS URBANOS
}

\section{SIMPLIFIED METHODOLOGY FOR EVALUATING THE POTENTIAL WIND ENERGY IN URBAN CENTERS}

\author{
Leandro Mendes da Silva ${ }^{1}$ \\ Escola de Engenharia Civil e Ambiental da Universidade Federal de Goiás, Goiânia, Go, Brasil, mendesleandro94@gmail.com \\ Loyde Vieira de Abreu-Harbich ${ }^{2}$ \\ Escola de Engenharia Civil e Ambiental da Universidade Federal de Goiás, Goiânia, Go, Brasil, loydeabreu@gmail.com
}

\section{Resumo}

Com o crescimento das cidades, produção de eletricidade e calor podem não ser suficientes para atender às novas demandas. A forma urbana pode promover possibilidades de geração de energias alternativas nas cidades. Este trabalho verifica o potencial do uso de energia eólica em centros urbanos a partir de um método simplificado que envolve análises qualitativas da forma urbana e quantitativas de dados meteorológicos para Goiânia. O método é caracterizado pelas seguintes etapas: a) Seleção da área de estudo; b) Desenvolvimento de um mapa temático onde cada zona se estabelece a partir de padrões de semelhança da topografia, altura das edificações, presença de vegetação, tipo de uso e ocupação; c) Análise do potencial de energia eólica para cada zona, segundo a NBR 6123; d) Desenvolvimento de diretrizes de desenho urbano que promovam a instalação de turbinas eólicas em edifícios de algumas zonas da cidade. Foram identificadas nove zonas com formas urbanas distintas, sendo que aquelas com alta densidade de ocupação apresentaram maior potencial para geração de energia eólica durante os meses de agosto a outubro - meses com maior demanda de energia para aclimatação de ambientes internos, o que sugere que a implantação de edifícios com mais de 40 pavimentos em áreas com baixa densidade pode melhorar a capacidade de micro geração de energia eólica nas cidades. Diretrizes de planejamento que visam a eficiência energética e, principalmente, sustentabilidade urbana, dependem da avaliação de múltiplos critérios.

Palavras-chave: Energias renováveis. Energia eólica. Planejamento urbano. Planejamento energético.

\begin{abstract}
With urban growth, electricity and heat production may not be enough to meet new demands. The urban form can promote possibilities of alternative energy generation in the cities. This work verifies the potential of wind energy use in cities from a simplified methodology that involves qualitative analyses of the urban form and quantitative meteorological data for Goiania. The method is characterized by the following steps: a) Selection of the study area; b) Development of a thematic map where each zone is established from the similarity patterns of the topography, height of the buildings, presence of vegetation, type of use and occupation; c) Analysis of the wind energy potential for each zone, according to NBR 6123; d) Development of urban design guidelines that promote the installation of wind turbines in buildings in some areas of the city. Nine zones were identified, within which those with high occupancy density presented the great potential for wind energy during August to October, which are the months with higher energy demand for acclimatization of indoor environments. It suggests that the implementation of buildings with more than 40 floors in areas with low density can improve the capacity of micro generation of wind power in cities. Urban guidelines that aim at energy efficiency and, especially, urban sustainability, depend on the evaluation of multiple criteria.
\end{abstract}

Keywords: Renewable energies. Wind Energy. Urban planning. Energy planning.

\section{How to cite this article:}

SILVA, Leandro Mendes da; ABREU-HARBICH, Loyde Vieira de. Metodologia simplificada para avaliação do potencial de energia eólica em centros urbanos. PARC Pesquisa em Arquitetura e Construção, Campinas, SP, v. 8, n. 1, p. 46-58, mar. 2017. ISSN 1980-6809. Disponível em: <https://periodicos.sbu.unicamp.br/ojs/index.php/parc/article/view/8648501>. Acesso em: 09 set. 2017. doi:http://dx.doi.org/10.20396/parc.v8i1.8648501. 


\section{Introdução}

A demanda por energia elétrica vem aumentando, gradativamente, em todo o mundo. Entre os anos de 2015 e 2016, o crescimento registrado foi de 1,0\% (BP, 2017). No Brasil, em decorrência da situação de retração econômica em que o país se encontra, no mesmo período, houve um decréscimo de $0,9 \%$ no consumo interno do país; apesar disso, uma melhora nas condições econômicas do Brasil é esperada, resultando na estimativa de aumentos médios de 3,7\% ao ano até o fim de 2026 (EPE, 2017a; EPE, 2017b).

O aumento do consumo de energia pode ser explicado pelo crescimento da população nas cidades e também das novas demandas energéticas com, principalmente, a climatização dos ambientes internos. O incremento do poder aquisitivo da população brasileira nos anos anteriores ao cenário de recessão atual e as alterações climáticas justificam isso. Outro fator a ser considerado é que as alterações nos padrões de uso e ocupação do solo geram aquecimento das áreas urbanas e, consequentemente, modificam os hábitos das pessoas em relação ao uso da energia.

No Brasil, a matriz elétrica tem em sua composição a maior parte proveniente de energias renováveis, representando $81,7 \%$ da geração total no país no ano de 2016 , das quais $68,1 \%$ são oriundas das usinas hidroelétricas. As hidroelétricas dependem de condições hidrológicas favoráveis, e um aumento da precipitação foi registrado no país em 2016. Isso fez com que a produção de energia derivada delas subisse, aproximadamente, $4,1 \%$ entre esses anos. (EPE, 2017a).

A hidroeletricidade também enfrenta dificuldades em sua expansão devido a todos os impactos socioambientais que a implantação de uma usina gera. Estes impactos estão normalmente associados à grande área necessária para reservar água, o que pode levar a desocupação de habitações locais e à mudança das características de seus ecossistemas, principalmente relacionados à fauna e flora. Somado a isso, o regime hidrológico da bacia local é modificado, gerando alterações nas condições climáticas da região (TOLMASQUIM, 2016).

Outras fontes de energia renováveis, como a eólica, podem complementar a demanda no período de estiagem, visto que as hidroelétricas reduzem a sua produção nesta época. No entanto, o uso dessas fontes em escalas significativas ainda é pouco aplicado, mas existem trabalhos que indicam que há grande potencial de geração a partir da fonte eólica. O Atlas do Potencial Eólico Brasileiro (AMARANTE et al., 2001) indica que o país possui potencial de geração de energia eólica de $143 \mathrm{GW}$, sendo aproximadamente $75 \mathrm{GW}$ somente na região Nordeste, principalmente nas regiões litorâneas. Já na região Centro-
Oeste, o valor do potencial de geração de energia é de 3,1 GW.

No Brasil, a energia elétrica oriunda da fonte eólica representou 5,4\% da matriz energética do país em 2016. A capacidade instalada das usinas eólicas do país cresceu $32,6 \%$ com relação ao ano de 2015 e representa a maior variação positiva na matriz energética brasileira (EPE, 2017a). Esses recursos têm natureza não controlável, são intermitentes e necessitam de grande desenvolvimento tecnológico para que a geração e o abastecimento sejam constantes (TOLMASQUIM, 2016).

A instalação de pequenas centrais de geração elétrica integradas ao tecido urbano é um assunto em destaque no Brasil, principalmente após a publicação da Resolução Normativa $n^{\circ} 482$ pela ANEEL (Agência Nacional de Energia Elétrica - responsável por regular e fiscalizar os serviços prestados pelas empresas de energia elétrica no país). A resolução regulamenta e estabelece condições gerais para o acesso da micro geração (potência instalada igual ou menor a $75 \mathrm{~kW}$ ) e de mini geração (potência instalada entre $75 \mathrm{~kW}$ e $3 \mathrm{MW}$ ) oriundas de fontes renováveis aos sistemas de energia elétrica. Ela tornou possível a implantação de um sistema de compensação: quando a energia gerada pelas pequenas centrais é superior à demanda do usuário, a energia produzida em excesso pode ser distribuída pela rede e isto será compensado posteriormente pela distribuidora de energia local (BRASIL, 2012).

Estes incentivos governamentais são o caminho para que as implantações dessas pequenas centrais de geração elétrica se disseminem e passem a ser mais utilizadas no Brasil como um todo. Devido às limitações de espaço, a implantação de turbinas eólicas em edifícios altos ou, até mesmo, em picos de morros situados dentro do perímetro urbano, seriam opções viáveis.

A forma da cidade pode promover ou reduzir o regime de ventos, dependendo da porosidade urbana. Um estudo recente realizado em Hong Kong observou que, à medida em que a altura das edificações se eleva, aumenta a velocidade dos ventos, que pode chegar a $11 \mathrm{~m} / \mathrm{s}$ no topo de um edifício de $450 \mathrm{~m}$ (YUAN; NG, 2012). A densificação das áreas urbanas pode ser um fator que aumenta o potencial para geração de energia eólica em centros urbanos. No entanto, outros fatores como topografia, altitude e proximidade com o mar ou corpos d'água, presença de vegetação entre outros, também devem ser considerados na análise da distribuição do vento nas cidades (KATZSCHNER,1997; ASSIS; FROTA, 1999; STEWARD; OKE, 2012; MASIERO; SOUZA, 2015)

Mesmo sabendo que o potencial para o uso de energia eólica no Centro-Oeste é baixo em relação às outras 
regiões do Brasil, uma avaliação simplificada baseada em dados meteorológicos obtidos no sítio urbano e no estudo da conFiguração urbana pode ser útil para prever o potencial de energia eólica no ambiente urbano. Ao mesmo tempo, o planejamento urbano pode ser utilizado para promover a inserção de turbinas eólicas urbanas.

Buscando analisar as possibilidades de aplicação de uma fonte alternativa de geração de energia, a energia eólica, para a micro e mini geração na cidade de Goiânia - GO, este trabalho tem como objetivo analisar este potencial a partir de dados meteorológicos e da morfologia urbana.

\section{Metodologia}

\section{Procedimentos de análise}

Para alcançar os objetivos propostos, as seguintes etapas são necessárias:

a) Seleção da área de estudo;

b) Desenvolvimento de um mapa temático baseado na análise qualitativa de variáveis da forma urbana como topografia, altura e largura das edificações, uso e ocupação do solo e presença de vegetação urbana. Essa metodologia se baseia na metodologia de Katzschner (1997) e Stewart e Oke (2012).

c) Análise do potencial de energia eólica urbana, realizado de acordo com as seguintes etapas:

- Levantamento de dados meteorológicos dos últimos 10 anos;

- Tratamento dos dados meteorológicos de modo a extinguir medições repetidas ou lidas como "NULL";

- Calibração da velocidade do vento para cada zona climática urbana desenvolvida na etapa anterior segundo a NBR 6123- Forças devidas ao vento em edificações (ABNT, 1988);

- Seleção de turbinas eólicas passíveis de serem instaladas nos edifícios;

- Cálculo de diferentes fatores de capacidade de acordo com as turbinas eólicas selecionadas;

- Análise do potencial de uso de energia eólica no centro urbano, segundo Allan e Billinton (2000)

d) Desenvolvimento de diretrizes de desenho urbano que promovam a instalação de turbinas eólicas em edifícios de algumas zonas da cidade.

\section{Área de estudo}

Goiânia ( $\left(16^{\circ} 40 \mathrm{~S} ; 49^{\circ} 15 \mathrm{~W} ; 749 \mathrm{~m}\right)$ é a segunda capital mais populosa do Centro-Oeste do Brasil, sendo a capital mais próxima da capital federal Brasília. Segundo o IBGE (2015), a população de Goiânia é de cerca de 1,4 milhões de habitantes, com densidade habitacional de 1.782,5 habitantes $/ \mathrm{km}^{2}$. Segundo o Instituto Nacional de Meteorologia - INMET (2016), Goiânia apresenta um regime pluviométrico bem definido, conFigurando uma estação seca (entre os meses maio a outubro) e outra chuvosa (novembro a janeiro). O índice pluviométrico é de $1570 \mathrm{~mm}$ por ano. Os índices de umidade relativa variam de $52 \%$, em agosto (mês mais seco do ano), a $82 \%$, no período de dezembro a março. A média da temperatura do ar nos últimos dez anos é de $24^{\circ} \mathrm{C}$, porém no período da tarde, a média das temperaturas fica em torno de $29^{\circ} \mathrm{C}$. Salienta-se que os meses mais quentes são agosto, setembro e outubro, com temperaturas acima de $29^{\circ} \mathrm{C} \mathrm{em}$ $25 \%$ das horas (CHAVES; ABREU-HARBICH, 2016).

A densificação nas regiões centrais da cidade tem se intensificado nos últimos anos, gerando padrões de uso e ocupação diferentes, modificando a rugosidade do solo urbano, e, por consequência, modificando o clima urbano. Por isso, foi delimitada uma área de estudos dentro do município de Goiânia, conforme representado na Figura 1.

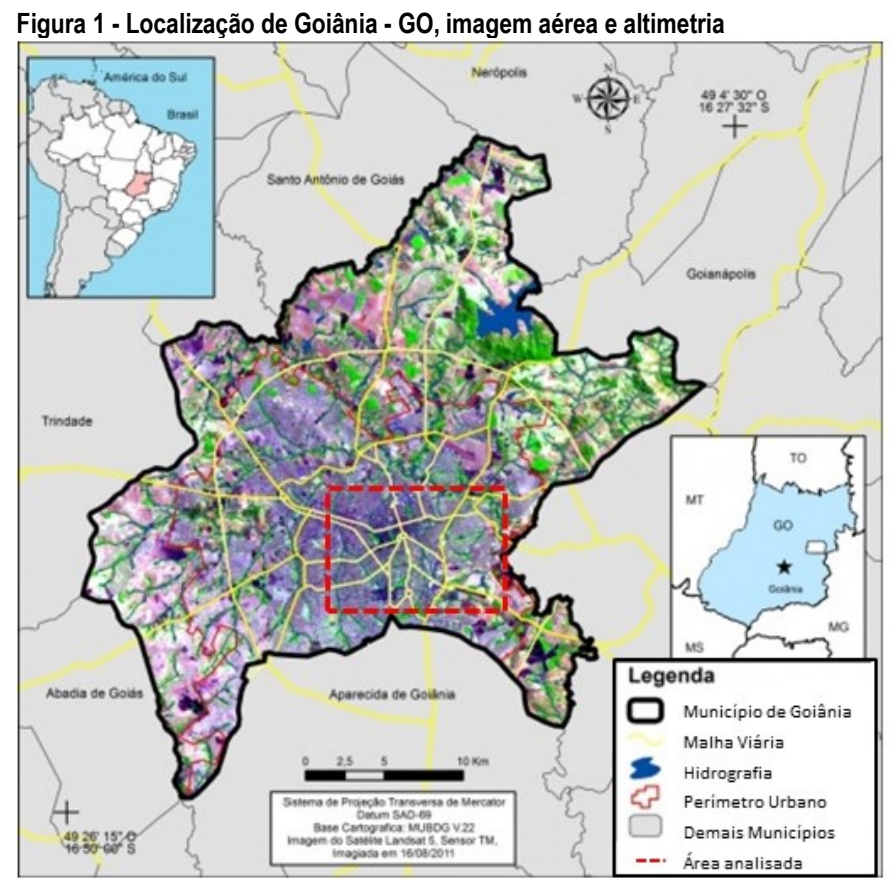

Fonte: Adaptado do LAPIG, 2011 e SOUZA; FERREIRA, 2012

\section{Desenvolvimento do Mapa Temático}

Para a definição do mapa temático, tomou-se como base a metodologia de Katzschner (1997), em que é realizada uma análise qualitativa da topografia, cobertura vegetal, uso e ocupação do solo e altura das edificações. A Figura 2 apresenta mapas temáticos do relevo e densidade de ocupação. 


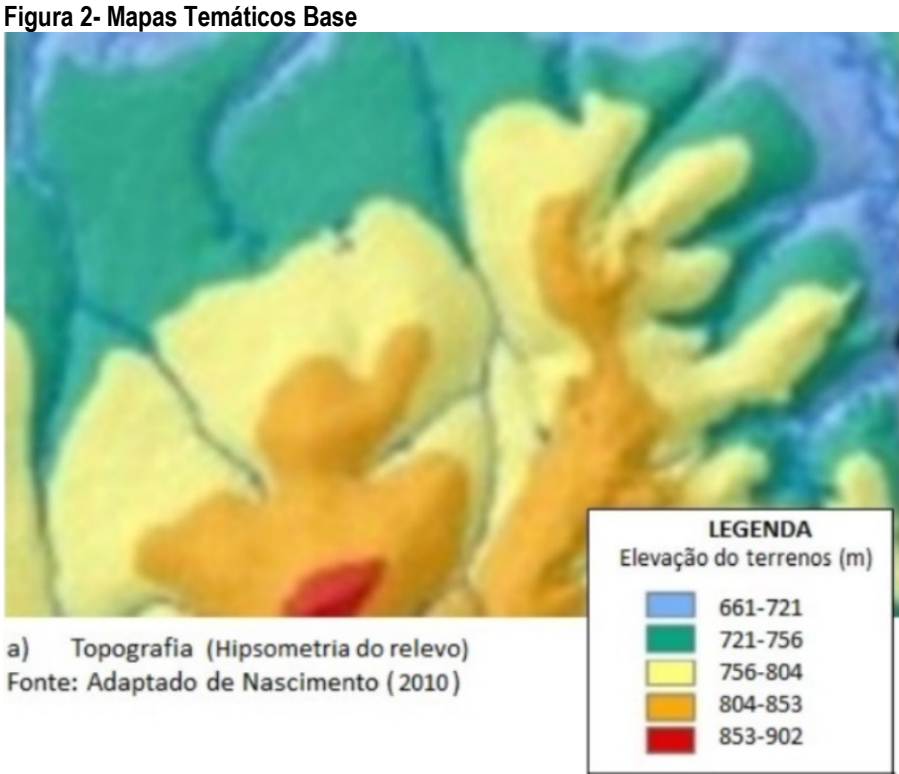

Fonte: Os Autores.

Para analisar a topografia, foi utilizado o mapa temático pré-existente sobre o relevo de Goiânia, desenvolvido por Nascimento (2011). Alves et al. (2011) observaram que a topografia de Goiânia é acidentada em até $8 \%$ e pouco rugosa, não influenciando de maneira significativa no regime de ventos.

Para avaliar a densidade de ocupação e presença de áreas verdes, a imagem aérea da área de estudo obtida pelo site do LAPIG (IESA, 2017) foi analisada pelo software de geoprocessamento rápido MultiSpec. A área de estudo foi classificada nas seguintes categorias: áreas verdes, áreas livres (asfalto), alta, média e baixa densidade de ocupação.

No mapa temático de ocupação, foi observada a existência de áreas que possuem o mesmo padrão, denominadas "clusters". Foram selecionados recortes de 150 x $150 \mathrm{~m}$ dentro dos "clusters", para uma avaliação mais detalhada. A partir de um levantamento de campo, foram calculadas a altura média das edificações, a relação altura e largura dos edifícios (H/W) e a taxa de ocupação do lote.

A separação das classes de alturas das edificações realizadas neste estudo considerou o processo histórico de densificação urbana de Goiânia. A cidade foi fundada em 1930, com a concentração da maioria das edificações na parte central da cidade, e a presença de edifícios de até três pavimentos nos setores Central e Sul. Parte deste plano urbanístico é mantido até os dias de hoje. Na década de 1960, o Plano Diretor do Arquiteto Luís Saia propôs a verticalização de áreas centrais, onde foram construídos edifícios com cerca de dez pavimentos, principalmente no Setor Central. Na década de 80 , houve políticas para incentivar a verticalização de algumas áreas da cidade, como os setores Aeroporto, Oeste e Bueno, construindo edifícios de 10 a 20 pavimentos. Na década de 90,

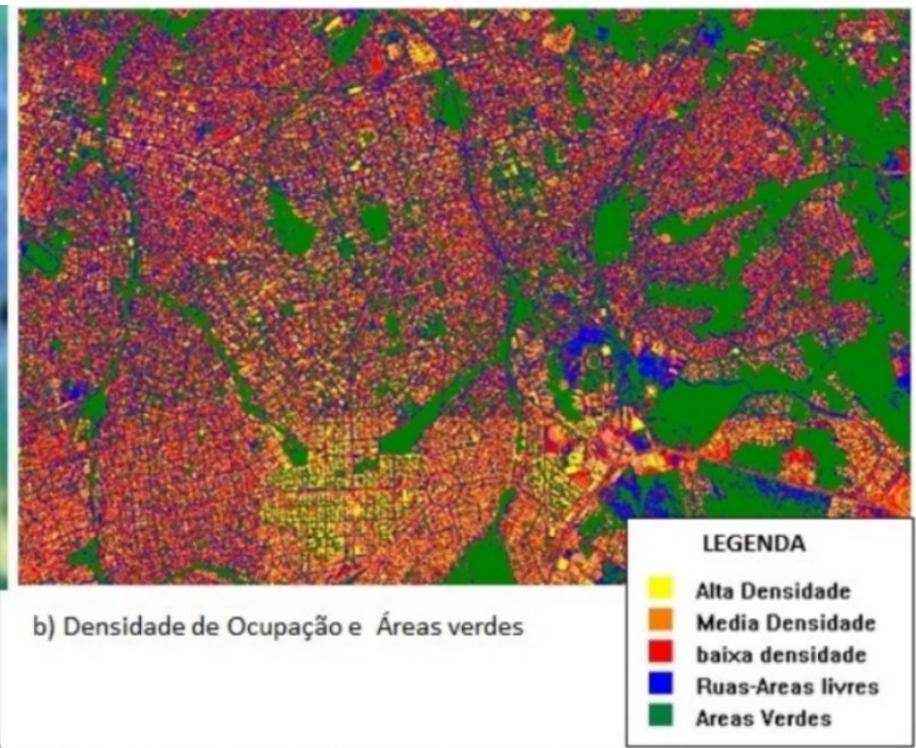

observou-se o adensamento de áreas próximas aos parques, com edifícios com altura entre 60 e $90 \mathrm{~m}$. Após 2007, a prefeitura liberou a construção de edifícios de altíssima verticalidade, com mais de $90 \mathrm{~m}$, a partir do pagamento de uma outorga onerosa (BELLORIO, 2013). Logo, os intervalos das alturas das edificações foram classificados segundo os seguintes padrões de verticalização: baixo (até $6 \mathrm{~m}$ ); médio (de 6 a $30 \mathrm{~m}$ ), médio-alto (de 30 a $60 \mathrm{~m}$ ), alto de (45 a $90 \mathrm{~m})$ e altíssimo (de 90 a 120 m), área dispersão da verticalização (20 a 50 $\mathrm{m})$.

\section{Levantamento de dados meteorológicos}

Os dados utilizados neste estudo (temperatura, umidade relativa, velocidade do ar, pressão atmosférica, radiação solar e precipitação) foram obtidos através da estação meteorológica do aeroporto Santa Genoveva, que se encontra em uma área urbana, livre de obstáculos $\left(16,64^{\circ}\right.$ $\mathrm{S} ; 49,22 \mathrm{~W}, 727 \mathrm{~m})$. O período estudado é de 10 anos (01 janeiro de 2005 a 31 de dezembro de 2014), com intervalo de dados horário. Os dados foram obtidos pelo site do INMET (2016).

Os dados meteorológicos foram analisados com o auxílio de uma planilha no software Excel. O primeiro passo foi identificar os dados faltantes no arquivo: algumas falhas decorrentes de problemas de sensores ou sinais de satélite fazem com que alguns dados sejam registrados como "NULL", o que significa, basicamente, que há um erro de leitura de dado. Foi feita uma análise dessas lacunas e foi adotado o seguinte critério:

Os erros identificados devem ser substituídos pela série de dados do mesmo dia e horário de um ano anterior com um comportamento similar ao daquele ano. Caso o ano 
anterior não tenha um comportamento similar, observouse o comportamento médio dos dados com os anos anteriores.

Os dados meteorológicos serão analisados a partir do cálculo das frequências, valores máximos e mínimos das temperaturas do ar, umidade relativa do ar, radiação solar e velocidade do vento.

\section{Calibração da velocidade do vento para cada zona climática urbana}

Para a análise do potencial eólico, os dados meteorológicos previamente verificados foram avaliados adaptando-se a velocidade do vento de acordo com a rugosidade do terreno, seguindo as diretrizes da NBR 6123 (ABNT, 1988).

A NBR 6123 (ABNT, 1988) define que a velocidade do vento que incide nas edificações é igual à velocidade característica (Vo) multiplicada por três fatores: S1, que leva em consideração a topografia do terreno; S2, que varia de acordo com a rugosidade do terreno, dimensões da edificação e altura sobre o terreno; e S3, um fator estatístico, baseado no grau de segurança requerido e a vida útil da edificação.

$$
V_{k}=V_{0} * S_{1} * S_{2} * S_{3}
$$

A velocidade característica é a velocidade obtida através dos dados meteorológicos previamente verificados.

A NBR 6123 (ABNT, 1988) estabelece que o fator topográfico $\mathrm{S} 1$ é igual a 1 quando o terreno é plano ou fracamente acidentado, como é o caso da cidade de Goiânia, objeto de estudo deste trabalho. As regiões que serão analisadas na cidade de Goiânia são residenciais ou comerciais e, de acordo com a norma, o fator estatístico S3 também é igual a 1 nessas situações.

Sendo assim, o fator que irá influenciar na adaptação da velocidade do vento é o fator rugosidade S2. A norma classifica a rugosidade do terreno em cinco categorias:

- Categoria 1: Superfícies lisas de grandes dimensões, com mais de $5 \mathrm{~km}$ de extensão, medidas na direção e sentido do vento incidente;

- Categoria 2: Terrenos abertos em nível ou aproximadamente em nível, com poucos obstáculos isolados, tais como árvores e edificações baixas;

- Categoria 3: Terrenos planos ou ondulados com obstáculos, tais como sebes e muros, poucos quebraventos de árvores, edificações baixas e esparsas;

- Categoria 4: Terrenos cobertos por obstáculos numerosos e pouco espaçados, em zona florestal, industrial ou urbanizada.
- Categoria 5: Terrenos cobertos por obstáculos numerosos, grandes, altos e pouco espaçados.

Para cada categoria diferente, o fator S2 varia em função da altura da edificação e do intervalo de medição das velocidades de vento. No caso, por se tratar de medições horárias realizadas nas estações meteorológicas, 0 intervalo entre as rajadas de vento considerado foi de 3600 segundos.

Para a determinação do fator S2 foram escolhidas seis situações distintas que serão analisadas de acordo com áreas dentro da cidade de Goiânia:

i. Uma edificação de 2 pavimentos (6 metros de altura) em uma região residencial não verticalizada, categoria 3;

ii. Uma edificação de 5 pavimentos (15 metros de altura) em uma região levemente verticalizada, categoria 4;

iii. Uma edificação de 10 pavimentos (30 metros de altura) em uma região verticalizada, categoria 5;

iv. Uma edificação de 20 pavimentos (60 metros de altura) em uma região verticalizada, categoria 5;

v. Uma edificação de 40 pavimentos (120 metros de altura) em uma região verticalizada, categoria 5;

vi. Uma situação hipotética em que ocorreria a construção de uma edificação de 40 pavimentos (120 metros de altura) em uma região residencial não verticalizada, categoria 3 .

Na NBR 6123 (ABNT, 1988) estão descritos os valores de S2 para determinados valores de altura dentro de cada categoria. Alguns dos dados necessários não estavam descritos na norma, e foi necessária a interpolação de valores próximos para defini-los. Os fatores S2 utilizados estão descritos na Tabela 1.

Tabela 1 - Fator S2 para as seis situações de análise
\begin{tabular}{|c|c|c|}
\hline Categoria & $\mathbf{Z}(\mathbf{m})$ & $\mathbf{S}_{2}$ \\
\hline \multirow{2}{*}{3} & 6 & 0.48 \\
\cline { 2 - 3 } & 120 & 0.91 \\
\hline 4 & 15 & 0.49 \\
\hline \multirow{3}{*}{5} & 30 & 0.42 \\
& 60 & 0.54 \\
\cline { 2 - 3 } & 120 & 0.68 \\
\hline
\end{tabular}

Fonte: ABNT, 1998. Adaptado pelos autores.

\section{Análise do potencial urbano para o uso da energia eólica}

Com o auxílio do software Excel, os valores de velocidade de vento dos 10 anos analisados foram adaptados de acordo com as situações descritas, e, por fim, foram montados gráficos de frequência mensal de velocidade do vento na cidade de Goiânia. Os intervalos das frequências de velocidade foram definidos considerando turbinas 
eólicas de pequeno porte, normalmente aplicadas em regiões urbanas, onde a velocidade de cut-in (velocidade onde a turbina passa a gerar energia elétrica) é de aproximadamente $2,5 \mathrm{~m} / \mathrm{s}$ e a velocidade de cut-out (quando a turbina para de gerar energia elétrica) pode chegar a $20 \mathrm{~m} / \mathrm{s}$, podendo variar de acordo com o fabricante e modelo da turbina (IEC 61400-2, 2006; CACE, 2006). Na Figura 3, pode-se observar a curva de potência de uma típica turbina de geração eólica.

Figura 3 - Curva de potência de um aerogerador típico

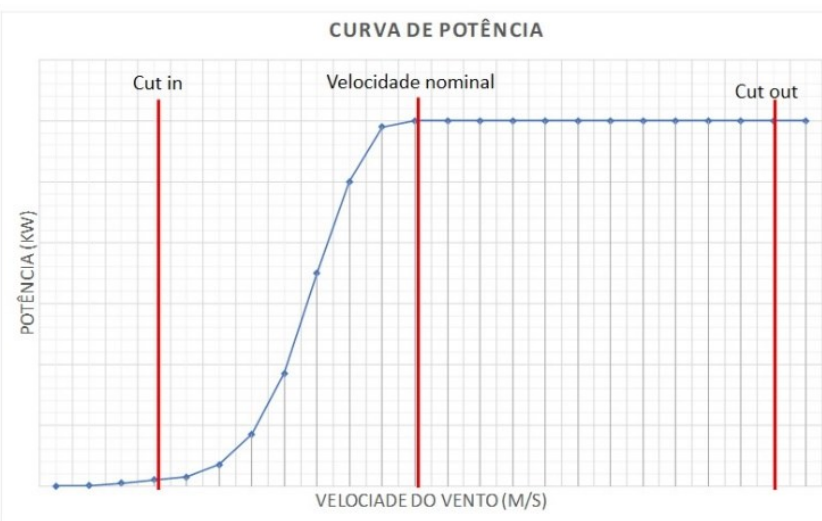

Fonte: Adaptado de Tolmasquim, 2016. Energia Renovável: Hidráulica, Biomassa, Eólica, Solar, Oceânica

A partir da velocidade do vento e de sua disponibilidade ao longo do ano, a análise do potencial eólico foi realizada através do Fator de Capacidade. De acordo com Leite, Borges e Falcão (2006), este fator é definido como a razão entre a EAWE (Expected Available Wind Energy), que consiste na quantidade de energia que pode ser gerada durante $\mathrm{o}$ ano sem considerar eventuais perdas na turbina eólica, e a IWE (Installed Wind Energy), que é a potência eólica instalada multiplicada pelo número de horas em um ano, que representa o valor máximo de energia extraída ao longo deste. A equação a seguir descreve esta relação.

$$
\mathrm{FC}=\frac{\mathrm{EAWE}}{\mathrm{IWE}}
$$

A EAWE é calculada através do produto da potência do vento disponível no local (medida através da estação meteorológica) pelo potencial máximo de extração de energia $\left(\mathrm{C}_{\mathrm{p}}\right)$ de uma turbina eólica predefinida, calculado de acordo com a seguinte equação:

$$
C_{p}=\frac{P}{\frac{1}{2}\left(\rho A v_{\text {nom }}^{3}\right)}
$$

Onde $\mathrm{P}$ é a potência instalada da turbina, $\rho$ é a massa específica do $\operatorname{ar}\left[\mathrm{kg} / \mathrm{m}^{3}\right]$, A é a área seção transversal $\left[\mathrm{m}^{2}\right]$ e $\mathrm{V}_{\text {nom }}$ é sua velocidade nominal $(\mathrm{m} / \mathrm{s})$

A EAWE é calculada para medições de velocidade de vento maiores que a velocidade de cut-in da turbina analisada. Os valores calculados para cada velocidade foram, então, somados, obtendo-se a EAWE anual.

Foram calculados os Fatores de Capacidade para cada mês do ano utilizando as suas características médias, e as análises foram feitas com o Fator de Capacidade médio anual.

\section{Seleção de turbinas eólicas}

A escolha das turbinas e suas características se deu baseada em um estudo de caso realizado no Reino Unido com turbinas de eixo horizontal em diferentes localizações. As turbinas foram instaladas e as medições realizadas pelo Energy Saving Trust entre 2008 e 2009, e os resultados foram analisados por James et al. (2010) para verificar a viabilidade econômica da instalação das turbinas voltadas para micro geração de energia eólica.

As principais características das turbinas escolhidas estão descritas na Tabela 2. As duas turbinas são de eixo horizontal, mas a turbina 1 apresenta uma seção menor do que a turbina 2. Ambas são parecidas em relação à velocidade nominal e a velocidade cut-in, no entanto, a potência instalada da turbina 2 é $0,5 \mathrm{~kW}$ maior que a da turbina 1 .

Tabela 2 - Modelos de turbinas eólicas escolhidos
\begin{tabular}{|l|c|c|l|c|c|}
\hline \multicolumn{3}{|c|}{ TURBINA 1} & \multicolumn{3}{c|}{ TURBINA 2} \\
\hline Nome: & \multicolumn{2}{|c|}{ Turbina 1} & Nome: & \multicolumn{2}{c|}{ Turbina 2} \\
\hline Área de Seção: & 2,54 & $\mathrm{~m}^{2}$ & Área de Seção: & 3,46 & $\mathrm{~m}^{2}$ \\
\hline Cp & \multicolumn{2}{|c|}{0,37} & Cp & \multicolumn{2}{|c|}{0,36} \\
\hline Potência Instalada: & 1.000 & $\mathrm{~W}$ & Potência Instalada: & 1.500 & $\mathrm{~W}$ \\
\hline Velocidade nominal: & 12,00 & $\mathrm{~m} / \mathrm{s}$ & Velocidade nominal: & 12,50 & $\mathrm{~m} / \mathrm{s}$ \\
\hline Velocidade cut-in: & 2,50 & $\mathrm{~m} / \mathrm{s}$ & Velocidade cut-in: & 2.30 & $\mathrm{~m} / \mathrm{s}$ \\
\hline Velocidade cut-out: & 50,00 & $\mathrm{~m} / \mathrm{s}$ & Velocidade cut-out: & \multicolumn{3}{c|}{ Não há } \\
\hline
\end{tabular}

Fonte: James et al., 2010. Implications of the UK field trial of building mounted horizontal axis micro-wind turbines. Adaptado pelos autores.

\section{Resultados e Discussões}

\section{Mapa temático}

Foram identificadas nove zonas principais, que variam em função da altura da edificação, da área de ocupação do lote e da rugosidade (relação entre altura da edificação e largura da rua) observadas. A imagem de satélite foi, então, combinada com as zonas estabelecidas, e a Figura 4 apresenta o mapa desenvolvido.

No mapa é possível localizar cada zona caracterizada na Tabela 3. Além dos critérios utilizados para calibrar a velocidade do vento para a área urbana, rugosidade do terreno observada e altura das edificações, este mapa temático considerou fatores que podem influenciar na permeabilidade do vento, tais como ocupação da área do lote, relação altura e largura das edificações e homogeneidade das conFigurações urbanas. 


\section{Calibração da velocidade do vento para cada zona climática urbana}

Para determinar o fator S2, as seis situações distintas estabelecidas na metodologia deste estudo foram correlacionadas com as zonas climáticas selecionadas na etapa anterior. Assim, a situação "i" corresponde à Zona 2, situação "ii" à Zona 4; situação "iii" à Zona 7; situação "iv" à Zona 8; situação "v" à Zona 9; e a situação "vi" é uma situação hipotética que representa o processo de verticalização da Zona 2.

Após a adaptação das diferentes velocidades de vento, medidas na estação meteorológica, de acordo com as diferentes rugosidades e situações anteriormente estabelecidas, foi possível obter uma série de gráficos com a distribuição de velocidades de vento médias mensais (Tabela 4).

Os gráficos apresentados a seguir mostram que a maior parte do vento incidente sobre a cidade, independentemente da situação analisada e da rugosidade local, possui valores iguais a zero ou menores que 2,50 $\mathrm{m} / \mathrm{s}$. No caso da situação iii, em um edifício de 10 pavimentos (com altura equivalente de 30 metros) inseridos numa zona verticalizada de categoria 5, os valores menores que $2,50 \mathrm{~m} / \mathrm{s}$ representam, em média, $99,80 \%$ do total de ventos registrados.

Tabela 3 - Diferentes rugosidades, alturas médias, ocupação do lote e legenda equivalente do Mapa

\begin{tabular}{|c|c|c|c|c|c|}
\hline $\begin{array}{c}\text { Categoria } \\
\text { equivalente } \\
\text { na NBR } \\
6123\end{array}$ & $\begin{array}{c}\text { Altura } \\
\text { média } \\
\text { das } \\
\text { edificaçõ } \\
\text { es (m) }\end{array}$ & $\begin{array}{c}\text { Relação } \\
\text { (H/W) }\end{array}$ & $\begin{array}{c}\text { Ocupaçã } \\
0 \\
\text { observad } \\
\text { a }\end{array}$ & Legenda & Zona \\
\hline \multirow{3}{*}{3} & $<6$ & $0-0,5$ & $50 \%$ & & 1 \\
\hline & $<6$ & $0,5-1,0$ & $80 \%$ & & 2 \\
\hline & $<6$ & $1,0-1,5$ & $100 \%$ & & 3 \\
\hline \multirow{2}{*}{4} & $<30$ & $1,0-1,5$ & $80 \%$ & & 4 \\
\hline & $<30$ & $1,0-1 ., 5$ & $100 \%$ & & 5 \\
\hline \multirow{4}{*}{5} & $20-50$ & $1,5-2,5$ & $80 \%$ & & 6 \\
\hline & $30-60$ & $1,0-2,0$ & $80 \%$ & & 7 \\
\hline & $45-90$ & $2,0-4,0$ & $80 \%$ & & 8 \\
\hline & $90-120$ & $4,0-6,0$ & $60 \%$ & & 9 \\
\hline \multicolumn{4}{|c|}{ ÁREAS VERDES } & & \\
\hline
\end{tabular}

Figura 4 - Mapa de morfologia urbana da cidade de Goiânia - GO

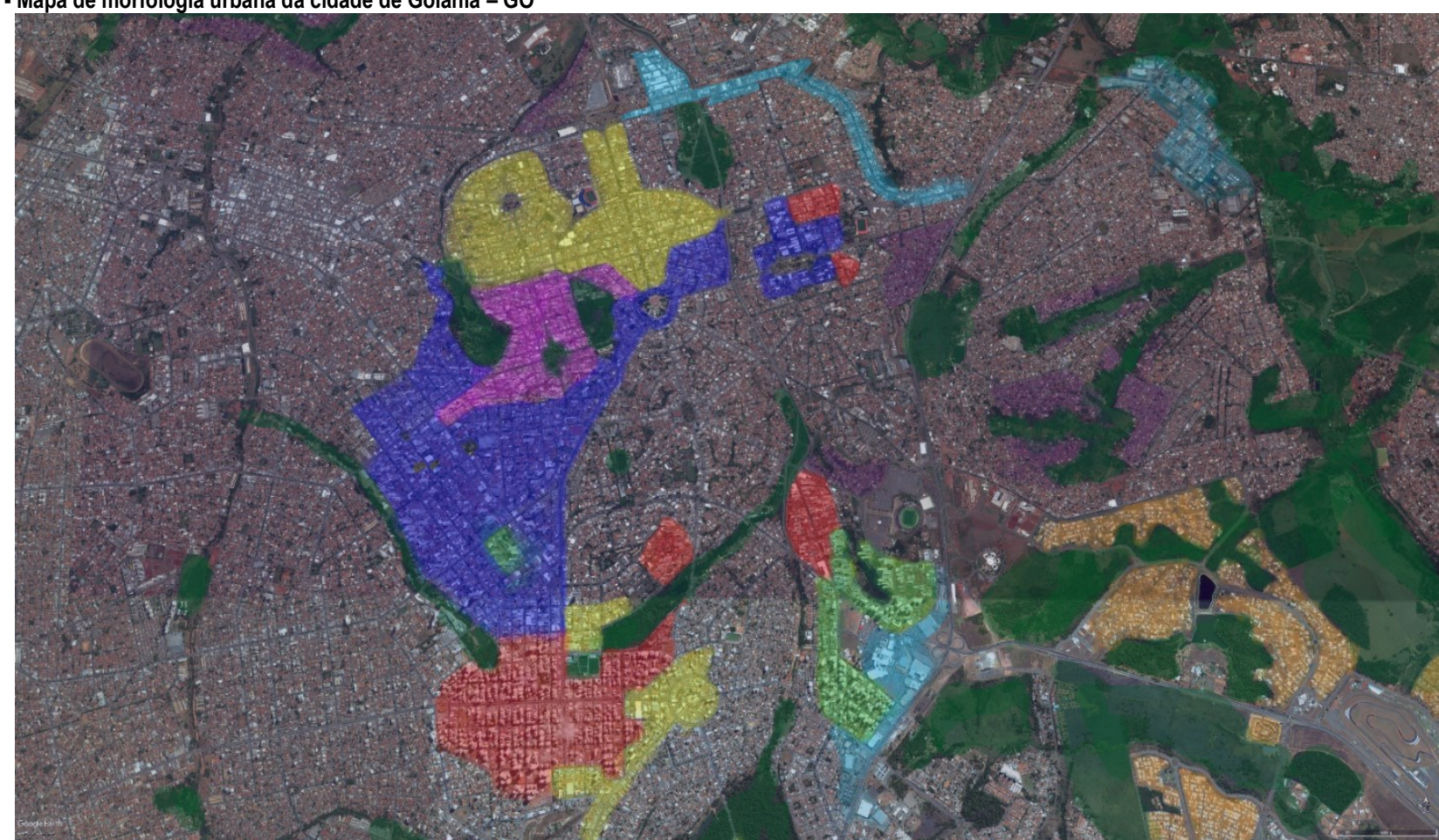

Fonte: Os Autores 
SILVA, Leandro Mendes da; ABREU-HARBICH, Loyde Vieira de.

Metodologia simplificada para avaliação do potencial de energia eólica em centros urbanos

\section{Tabela 4 - Distribuição de ventos em edifícios nas situações analisadas}

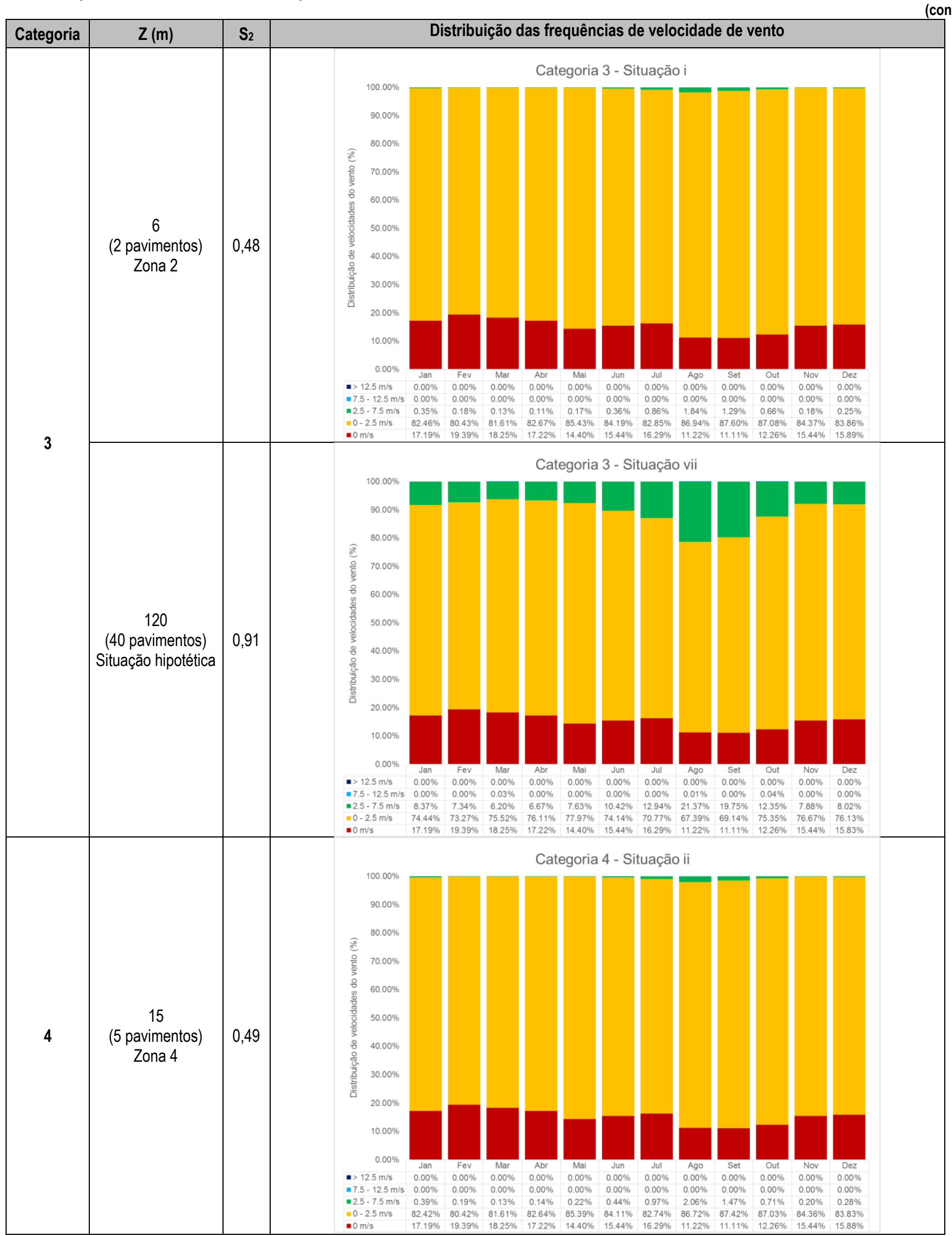


Tabela 4 - Distribuição de ventos em edifícios nas situações analisadas

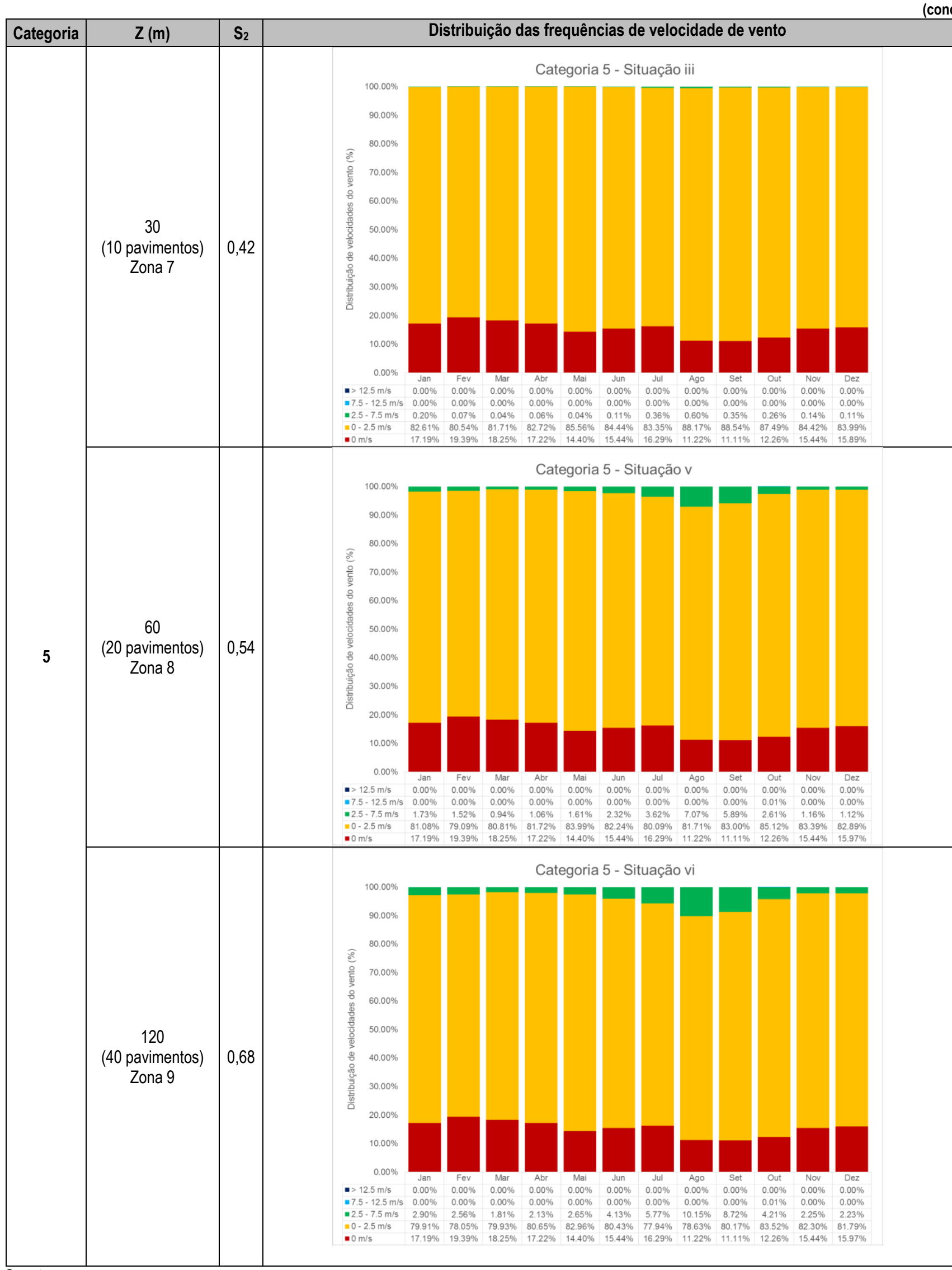


A situação "i” se mostra a situação mais desfavorável para a possível geração eólica, visto que a maioria das turbinas eólicas de pequeno porte voltadas para o ambiente urbano possuem velocidade cut-in de, pelo menos, $2,50 \mathrm{~m} / \mathrm{s}$.

Já na situação vii, considerada a situação mais favorável para a eventual geração, em que um edifício de 40 pavimentos (com altura equivalente de 120 metros) é inserido numa zona não verticalizada de categoria 3 , os valores menores que $2,50 \mathrm{~m} / \mathrm{s}$ representam, em média, $89,25 \%$ dos valores.

Apesar das velocidades obtidas apresentarem valores médios muito baixos, elas não são suficientes para classificar se a implantação de turbinas eólicas de pequeno porte em edificações é viável ou não, sendo necessárias análises adicionais quanto ao seu fator de capacidade.

\section{Potencial de uso de energia eólica no centro urbano}

Para o cálculo dos diferentes fatores de capacidade de acordo com as turbinas eólicas selecionadas e descritas no capítulo anterior, deve-se, primeiramente, calcular a IWE (Installed Wind Energy). Esta é obtida através do produto da potência instalada da turbina $(\mathrm{em} \mathrm{W})$ pela quantidade de horas presentes em um ano. Adotando-se um ano com 365 dias, obteve-se que a IWE da Turbina 1 é de 8.760 $\mathrm{kW}$, enquanto a da Turbina 2 é de $13.140 \mathrm{~kW}$.

Para o dimensionamento da EAWE (Expected Available Wind Energy), foram consideradas, em cada situação, apenas as velocidades com valores maiores que as velocidades cut-in das turbinas, sendo a da Turbina 1 de $2,50 \mathrm{~m} / \mathrm{s}$ e da Turbina 2 de $2,30 \mathrm{~m} / \mathrm{s}$. Em seguida, a energia obtida é dividida pelo IWE, obtendo-se o fator de capacidade para cada turbina em cada situação.

O menor fator de capacidade registrado foi na Situação iii com a utilização da Turbina 1 , com $0,003 \%$. Já o maior valor obtido foi na Situação vii, utilizando-se a Turbina 2; o valor obtido foi de $0,35 \%$. Um gráfico comparativo entre os diferentes fatores de capacidade e situações de análise é apresentado na Figura 5.

Figura 5 - Comparativo entre os fatores de capacidade de cada turbina para todas as situações de análise

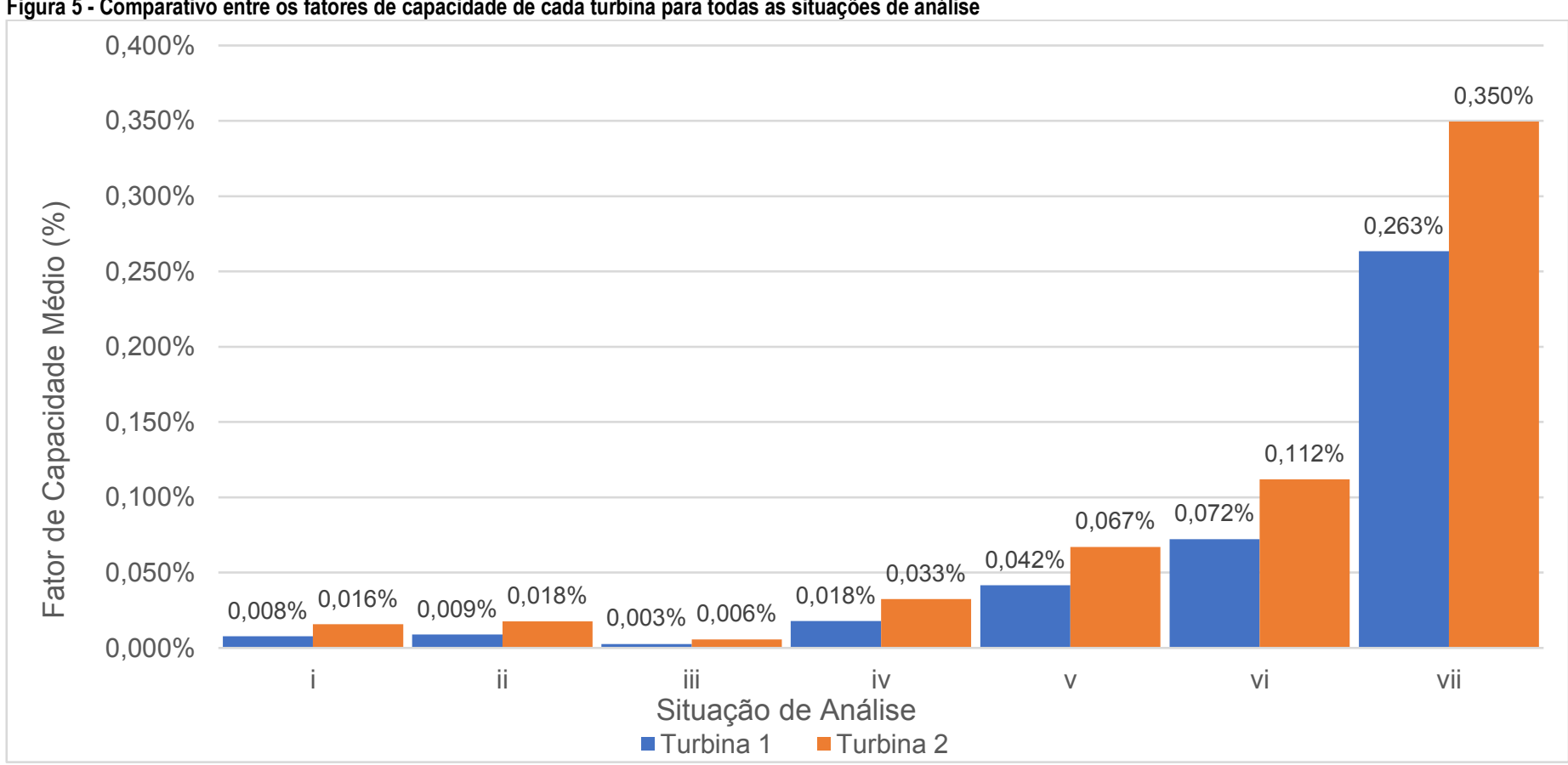

Fonte: Os autores

James et al. (2010) concluíram em seu trabalho que, para que a instalação de uma turbina eólica de pequena dimensão apresente viabilidade financeira, o fator de capacidade deve ser de, no mínimo, 6\%. Apesar de ser um estudo de caso realizado no Reino Unido e que, portanto, analisa a viabilidade econômica a partir das características do mercado britânico, pode-se estender essa análise para Goiânia, visto que a relação entre o preço do kWh e o custo de equipamento no Reino Unido é similar ao Brasil.
Como o maior fator de capacidade encontrado para a cidade de Goiânia foi de $0,350 \%$, é possível concluir que a instalação de turbinas eólicas voltadas para micro geração no tecido urbano goianiense não seria viável.

\section{Considerações Finais}

Com o aumento do consumo de energia elétrica no Brasil e no mundo e o consequente aumento dos impactos ambientais associados às suas fontes de produção que atualmente compõem a matriz energética mundial, há uma 
enorme necessidade de se ampliar a utilização de fontes consideradas limpas (ou renováveis) para a produção de energia elétrica.

A matriz energética brasileira é composta, em sua maioria, por energias oriundas de fontes renováveis, principalmente a energia hidroelétrica. As condições hidrológicas desfavoráveis pelas quais o país passa atualmente, porém, fizeram com que a participação da energia hidroelétrica na matriz energética diminuísse nos últimos anos. Buscando evitar a utilização em maior escala de energias oriundas de fontes não renováveis, é necessário se pensar em fontes alternativas renováveis para a produção de energia, como a eólica.

Este trabalho se propôs a identificar a verificar o potencial existente da utilização da energia eólica dentro do tecido urbano da cidade de Goiânia - GO para a produção de energia elétrica, a partir de dados obtidos de uma estação meteorológica.

A partir do estudo já elaborado por Amarante et al. (2001), era esperado, em linhas gerais, que a energia eólica apresentasse baixo potencial de utilização. A partir de algumas suposições quanto às turbinas eólicas utilizadas na geração, foi possível observar que o potencial para a utilização da energia eólica é praticamente nulo dentro do tecido urbano da cidade de Goiânia.

No entanto, a quantificação do potencial eólico utilizando dados climáticos de um período de 10 anos e a adaptação das velocidades do vento para a rugosidade encontrada na cidade pelo método da NBR 6123 (ABNT, 1988) possibilitou fazer uma análise rápida e mais próxima da realidade. Salienta-se que essa metodologia se baseia em estimativas de redução ou aumento da velocidade do vento de acordo com a rugosidade urbana.

Para estudos futuros, sugere-se uma calibração desse método a partir de uma análise na escala microclimática a partir do modelo WASP. Estanqueiro e Simões (2010) destacam a importância de realizar análises em escalas microclimáticas utilizando modelos como os CFDs (Computer Fluid Dynamics). Além isso, o levantamento de dados de velocidade e direção do vento no local onde se deseja instalar uma turbina de micro geração eólica, poderá trazer importantes resultados para avaliar 0 potencial eólico.

O desenvolvimento do mapa temático sobre a forma urbana da cidade de Goiânia - GO serviu para ilustrar as diferentes situações de análise estabelecidas na análise do potencial eólico. Esta metodologia auxilia na identificação de áreas potenciais para geração de energia eólica urbana.

A aplicação desse estudo em outras cidades auxiliará no desenvolvimento de planejamento estratégico focado na eficiência energética urbana, trazendo mais sustentabilidade às cidades brasileiras.

O mapa da forma urbana da cidade de Goiânia desenvolvido neste trabalho apresenta grande versatilidade quanto à sua possível utilização em trabalhos futuros: análises climáticas, de conforto térmico ou de eficiência energética normalmente são realizadas considerando as diferentes formas que compõem o tecido urbano, que foram verificadas, estabelecidas e ilustradas neste mapa, permitindo a sua utilização em trabalhos que sigam nesta área.

\section{Agradecimentos}

Agradecemos à CAPES (Coordenação de Aperfeiçoamento de Pessoal de Nível Superior) pela apoio financeiro e concessão de bolsa de pós-doutorado PNPD para o Programa de Pós-Graduação em Geotecnica, Estruturas e Construção Civil da Escola de Engenharia Civil e Ambiental da Universidade Federal de Goiás.

\section{Referências}

ABNT - ASSOCIAÇÃO BRASIELIRA DE NORMAS TÉCNICAS. NBR 6123: Forças devidas ao vento em edificações. Rio de Janeiro: ABNT, 1988.

ALLAN, Ronald N.; BILLINTON, Roy. Probabilistic assessment of power systems. In: IEEE Power \& Energy Society, 2000. Proceedings... v. 88, n. 2, p. 140-162, 2000.

ALVES, P.R. et al.. Avaliação da Impermeabilização do Solo na Área Urbana em Goiânia. In: XV SIMPÓSIO BRASILEIRO DE SENSORIAMENTO REMOTO - SBSR, Curitiba, Anais... Curitiba, p.0965, 2011

AMARANTE, Odilon A. et al. Atlas do potencial eólico brasileiro. Atlas do potencial eólico brasileiro. MME/Eletrobrás, 2001.

ASSIS, Eleonora S.: FROTA, Anesia B., Urban bioclimatic design strategies for a tropical city. Atmospheric Environment, v. 33, n. 24, p. 4135-4142, 1999. Elsevier Science. http://dx.doi.org/10.1016/S1352-2310(99)00155-7 
BELLORIO, G. B, Adensamento e Verticalização em Goiânia nos planos diretores (1968-2007). Dissertação (mestrado) em Desenvolvimento e Planejamento Territorial da Pontifícia Universidade Católica de Goiás

BRASIL. ANEEL. Resolução Normativa No 482, de 17 de abril de 2012. Estabelece as condições gerais para o acesso de microgeração e minigeração distribuída aos sistemas de distribuição de energia elétrica, o sistema de compensação de energia elétrica, e dá outras providências. Disponível em: <http://www2.aneel.gov.br/cedoc/ren2012482.pdf $>$. Acesso em 05 de julho de 2016

BP Global. BP Statistical Review of World Energy. Jun. 2017. Relatório. Disponível em: http://www.bp.com/en/global/corporate/energy-economics/statistical-review-of-world-energy.html

CACE, Jadranka et al. Urban wind turbines. Guidelines for small wind turbines in the built environment. p. 1-41, 2007.

CHAVES, V.L.ABREU-HARBICH, L. V.; Identificação do Ano Climático De Referência Para Goiânia - Goiás. In:XVI ENCONTRO NACIONAL DE TECNOLOGIA NO AMBIENTE CONSTRUÍDO, 2016, São Paulo Anais... São Paulo: USP, set 2016.

EPE - EMPRESA DE PESQUISA ENERGÉTICA. Balanço energético nacional 2017: ano base 2016. Ministério de Minas e Energia, 2017a.

EPE- EMPRESA DE PESQUISA ENERGÉTICA. Nota técnica DEA 001/17: Projeção da demanda de energia elétrica para os próximos 10 anos (2017-2026). Estudos da Demanda, 2017b.

ESTANQUEIRO, Ana; SIMÕES, Tereza. Aproveitamento de energia eólica em ambiente urbano e construído. Renováveis Magazine, v1, p. $44-49,2010$.

IBGE - INSTITUTO BRASILEIRO DE GEOGRAFIA E ESTATÍSTICA. Censo Demográfico da cidade de Goiânia - GO. 2015. Disponível em: <http://www.cidades.ibge.gov.br/xtras/perfil.php?lang=\& codmun=520870>. Acesso em de 07/07/2016.

ICE - INTERNATIONAL ELECTROTECHNICAL COMMISSION. IEC 61400-2: Wind turbines - art 2: Design requirements for small wind turbines. Genebra: International Electrotechnical Commission, 2006.

INMET - INSTITUTO NACIONAL DE METEOROLOGIA. Dados Meteorológicos. 2016. Disponível em: $<$ http://www.inmet.gov.br/portal>. Acesso em de 07/06/2016.

JAMES, P.A.B. et al. Implications of the UK field trial of building mounted horizontal axis micro-wind turbines. Energy Policy, [s.l.], v. 38, n. 10, p.6130-6144, out. 2010. Elsevier BV. http://dx.doi.org/10.1016/j.enpol.2010.05.070.

KATZSCHNER, L. Urban climate studies as tools for urban planning and architecture. In: IV ENCONTRO NACIONAL DE CONFORTO NO AMBIENTE CONSTRUÍDO, Salvador. Anais... Salvador, FAUFBA, ANTAC; 1997, p. 49-58.

LEITE, Andréa P.; FALCÃO, Djalma M.; BORGES, Carmen LT. Modelagem de usinas eólicas para estudos de confiabilidade. Sba: Controle \& Automação Sociedade Brasileira de Automática, v. 17, n. 2, p. 177-188, 2006.

MASIERO, Érico; SOUZA, Léa Cristina Lucas de. Improving urban thermal profile with trees and water features. Proceedings Of The Institution Of Civil Engineers - Urban Design and Planning, Thomas Telford Ltd.., v.169, n. 2, p.66-77, 2016. http://dx.doi.org/10.1680/jurdp.14.00063.

NASCIMENTO, D. T. F. Emprego de técnicas de sensoriamento remoto e de geoprocessamento na análise multitemporal do fenômeno de ilhas de calor no município de Goiânia-GO (1986/2010). Dissertação (Mestrado) - Universidade Federal de Goiás, Instituto de Estudos Sócio-Ambientais, 2010.

STEWART, I. D.; OKE, T. R.. Local Climate Zones for Urban Temperature Studies. Bulletin of the American Meteorological Society, [s.1.], v. 93, n. 12, p.1879-1900, dez. 2012. American Meteorological Society. http://dx.doi.org/10.1175/bams-d-11$\underline{00019.1 .0 \mathrm{ke}}$

SOUZA, S. B, FERREIRA, L.G. Analyse de température de surface en environnement urbain: une étude par télédétection de la ville de Goiânia, Goiás (2002-2011). Revue franco-brésilienne de géographie . n. 15. 2012. 
TOLMASQUIM, Mauricio Tiomno. Energia Renovável: Hidráulica, Biomassa, Eólica, Solar, Oceânica. Rio de Janeiro: EPE/MME, 2016.

YUAN, Chao; NG, Edward. Building porosity for better urban ventilation in high-density cities - A computational parametric study. Building and Environment, [s.1.], v. 50, p.176-189, abr. 2012. Elsevier BV.

http://dx.doi.org/10.1016/j.buildenv.2011.10.023.

\section{${ }^{1}$ Leandro Mendes}

Engenheiro Civil. Graduado pela Escola de Engenharia, Universidade Federal de Goiás. Endereço postal: Av. Universitária, 1488, Qd 86, Lt Área. St. Universitário, Goiânia, GO. CEP: 74605-220

\section{${ }^{2}$ Loyde Vieira de Abreu-Harbich}

Arquiteta e Urbanista. Mestrado em Engenharia Civil e Doutorado em Arquitetura, Tecnologia e Cidades, ambos pela Universidade Estadual de Campinas. Professora e Pesquisadora no Programa de Pós-Graduação em Geotécnica, Estruturas e Construção Civil na Escola de Engenharia, Universidade Federal de Goiás. Endereço postal: Av. Universitária, 1488, Qd 86, Lt Área. St. Universitário, Goiânia, GO. CEP: 74605-220 